\title{
BİLECİK BALLARININ MELISSSOPALİNOLOJİK VE KİMYASAL ÖZELLİKLERİ AÇISINDAN DEĞERLENDİRİLMESİ
}

\author{
Şaban Keskin*¹, Nazlı Mayda ${ }^{2}$, Merve Keskin ${ }^{1}$, Aslı Özkök ${ }^{3}$ \\ ${ }^{1}$ Bilecik Şeyh Edebali Üniversitesi, Sağllk Hizmetleri Meslek Yüksek Okulu, Gülümbe, Bilecik, Türkiye \\ ${ }^{2}$ Hacettepe Üniversitesi, Biyoloji Bölümü, Uygulamalı Biyoloji Anabilim Dalı, Beytepe, Ankara, Türkiye \\ ${ }^{3}$ Hacettepe Üniversitesi Arı ve Arı ürünleri Uygulama ve Araştırma Merkezi, Beytepe, Ankara, Türkiye
}

Geliş / Received: 19.07.2019; Kabul / Accepted: 13.01.2020; Online bask1 / Published online: 29.02.2020

Keskin, Ş., Mayda, N., Keskin, M., Özkök, A. (2020). Bilecik ballarının melissopalinolojik ve kimyasal özellikleri açısından değerlendirilmesi. GIDA (2020) 45(2) 275-289 doi: 10.15237/gida.GD19107

Keskin, S., Mayda, N., Keskin, M., Ö₹kök, A. (2020). Investigation of Bilecik. honeys in terms of melissopalynology and chemical analyses. GIDA (2020) 45(2) 275-289 doi: 10.15237/gida.GD19107

\section{ÖZ}

Balın içeriği toplandığı bölgenin florası, iklimsel özellikleri, toplanma zamanı ve şekli gibi birçok etkene göre farklllık gösterebilmektedir. Balın kalitesinin belirlenmesinde başta bitkisel orijini olmak üzere kimyasal ve antioksidan özelliklerinin de ortaya konulması gerekmektedir. Yapılan bu çalışmada Bilecik ilinden toplanan 16 adet bal örneği melissopalinolojik açıdan incelenmiş, balların nem, toplam fenolik madde miktarı, glukoz, fruktoz oranları ve aroma bileșenleri belirlenmiștir Elde edilen bulgular sonucu ballarda 20 familyaya ait 35 farklı bitki taksonuna rastlanmıştır. Toplam polen sayıları açısından değerlendirildiğinde 6 adet balın normal, 10 adet balın ise düşük kalitede oldukları görülmüştür. Balların nem içerikleri \%15.8 ile \%19.5 arasında değişmektedir. Balların fruktoz/glikoz (F/G) oranlarının ise 096 ile 1.19 aralığında olduğu belirlenmiştir. Ballarda toplam fenolik madde miktarı en düşük 33 mg GAE/ $100 \mathrm{~g}$ iken en yüksek 81 mg GAE/ $100 \mathrm{~g}$ olarak ölçülmüștür. GC-MS analizleri sonucu balların aldehitler, alifatik asit ve esterleri, alkoller, ketonlar, terpenler ve yağ asitleri gibi bileşik gruplarını içerdikleri gözlenmiştir.

Anahtar kelimeler: Bal, melissopalinolojik analiz, toplam fenolik madde, GC-MS, HPLC

\section{INVESTIGATION OF BILECIK HONEYS IN TERMS OF MELISSOPALYNOLOGY AND CHEMICAL ANALYSES}

\begin{abstract}
The composition of honey varies depending on many factors such as flora, climatic characteristics, collection time and stile. In determining the quality of honey, its chemical origin and antioxidant properties should be investigated. In this study, melissopalinological, moisture, total phenolic content, glucose and fructose ratio were measured in 16 honey samples collected from Bilecik province. Accordingly, 35 different plant taxa belonging to 20 families were found. When total pollen counts were evaluated, six honeys were found to be normal quality whereas ten honeys were considered to be low quality. The moisture content of honeys varied between $15.8 \%$ and $19.5 \%$. Fructose/glycose ratio of honeys was found to be between 0.96 and 1.19. Total phenolic content of honey sample was determined as the lowest value of $33 \mathrm{mg} \mathrm{GAE} / 100 \mathrm{~g}$ and the highest value of $81 \mathrm{mg}$ GAE/ $100 \mathrm{~g}$. GC-MS analysis showed that honey samples were rich in volatile components.
\end{abstract}

Keywords: Honey, melissopalynological analysis, total phenolic content, GC-MS, HPLC

\footnotetext{
*Yazışmalardan sorumlu yazar/ Corresponding author

$\square$ sabankeskin61@hotmail.com, $\quad 0(+90) 2282141641$

國 (+90) 2282141379
}

Şaban Keskin; ORCID no: 0000-0002-0287-4268

Nazlı Mayda; ORCID no: 0000-0002-7289-5830

Merve Keskin; ORCID no: 0000-0001-9365-334X

Aslı Özkök; ORCID no: 0000-0002-7336-2892 


\section{GİRİ̧}

Bal, bal arıları tarafindan toplanan balözünün değişime uğratılarak petek gözlerinde depolandığı, tatlı ve insanlar tarafindan doğal olarak tüketilen bir gıdadır (Mutlu vd., 2017). Bal arıları balözü olarak bitki çiçeklerinin salgiladığ1 nektarı toplayabildiği gibi, bazı bitkilerin üzerinde yaşayan böceklerin çıkardığı (salg1) ya da bazı özel hava koşullarında terleme yoluyla (basra) oluşan tatlı salgiları da toplayabilirler (Tutkun, 2006; Kolaylı vd., 2018). Dolayısıyla, ballar balözü kaynağına göre çiçek veya salg1 balı olarak sinıflandırılır. Türkiye zengin bitki örtüsü nedeni ile bol miktarda çiçek balı üretme potansiyeline sahiptir. Karışık çiçek ballarının yanı sıra ülkemizde iki tür salg1 balı üretilmektedir. Bunlar çam ağaçlarında beslenen bitki emici böceklerin (Marchalina bellenica) salgılarından üretilen çam balı ve meşe ağaçlarının terleme yoluyla yapraklarının salg1ladığ1 tatlı salgılardan üretilen meşe balıdır (Kolaylı vd., 2018).

Balın bileşimi öncelikle balözünün toplandığ1 bitkisel kaynağa bağlı olarak farklılık gösterir. Bununla birlikte mevsimsel şartlarda balın bileşimi üzerinde önemli etkiye sahiptir (Hasan, 2013). Temelde bal, glikoz ve fruktozun yoğunlaştırılmış bir karışımıdır. Bu iki monosakkaritin yanında balın bileşiminde disakkaritler ve oligosakkaritlerden oluşan birçok karbonhidrat türevi de bulunur. $\mathrm{Bu}$ ana bileşenlere ek olarak balın yapısında çok farklı bileşenler de eser düzeyde bulunmaktadır. Bunlar çeşitli mineraller, organik asitler, fenolik asitler, flavonoidler, vitaminler, enzimler ve diğer proteinler olarak siralanabilir (Bertoncelj vd., 2007; Karadal ve Yildırım, 2012).

Balın antioksidan özelliği içeriğindeki bu eser bileşenlerin türü ve miktarı ile orantılıdır. $\mathrm{Bu}$ bileşenlerin çeşidi ve miktarı balözünün kaynağına (flora) ve balın coğrafi orijinine bağlı olarak değişmektedir. Yapılan çalışmalar ile koyu renkli balların daha zengin polifenolik içeriğe ve dolayısı ile daha yüksek antioksidan kapasiteye sahip oldukları ortaya koyulmuştur (Tutkun, 2006; Bertoncelj vd., 2007, Kolaylı vd., 2018). Balın beslenme ve sağlık üzerine olan yeri insanlık tarihi boyunca bilinmekle birlikte son yillarda balın antioksidan özelliği ile sağlık üzerine olan etkileri arasında bir ilişki olduğu ifade edilmektedir. Antioksidan aktivitesi yüksek balların yaşlanmayı önleme, dejeneratif kalp ve sinir sistemi hastalıkları ve bazı yaraların iyileştirilmesinde etkili olabildiği ortaya koyulmuştur (Tutkun, 2006).

Melissopalinolojik analiz ise bal örneklerinin floral kaynaklarını belirlemede kullanılan önemli bir yöntemdir. $\mathrm{Bu}$ yöntemde bal örneklerinde bulunan polenler 1 şı mikroskobu altında incelenerek balın içerdiği polen türleri ve miktarları ortaya koyulmaktadır (Çelemli vd., 2018).

Bilecik ili, Marmara Bölgesi'nin güneydoğusunda Marmara, Karadeniz, İç Anadolu ve Ege bölgelerinin kesişim noktaları arasında bulunmaktadır. Değişen yükselti farklılıkları ve bunların yarattı̆̆ ekosistemler ile üç bitki coğrafyasının kesişim noktasında bulunma durumu Bilecik coğrafyasını çekici hale getirmektedir. İl topraklarının \%32'sini dağlar oluşturmaktadır. Dağlarında kızılçam, köknar, karaçam, sarıçam, kayın, ceviz, fındık, meşe, ladin, titrek kavak, funda, ihlamur, defne, böğürtlen, incir, dişbudak ve alıç ile kaplı ormanlık alanlar bulunur. Bununla birlikte, üçgüller, kekikler, yoncagiller gibi farklı familyalardan geniş bir çiçekli bitki örtüsüne de sahiptir (BEBKA, 2018).

Bu çalışmanın amacı Bilecik ilinde üretilen balların melissopalinolojik açıdan incelenmesi, nem, toplam fenolik madde, fruktoz, glukoz içerikleri ile uçucu bileşenlerin ve yağ asitlerinin belirlenmesidir. Böylece bölgede üretilen balların floral zenginlik ve içerik yönünden kaliteleri aydınlatılmış olacaktır.

\section{MATERYAL VE YÖNTEM}

Çalısmada kullanılan Fuksin, gliserol, metanol, asetonitril, folin reaktifi, sodyum karbonat, gallik asit, glikoz ve fruktoz Sigma Aldrich Chemie $\mathrm{GmbH}$ (Munich, Germany) firmasindan temin edilmiştir. Bütün çözeltiler saf su ile hazırlanmıştır. 


\section{Bal örneklerinin toplanması}

16 adet bal örneği 2018 ylı bal hasadından sonra Bilecik ilinde 14 farklı lokasyonda (Camiliyayla, Cihangazi, Deli Elmacık, Dodurga, Erikli, Sögüt/Hamitabat, İnhisar, Kurtköy, Koyunköy, Poyra, Saraycık, Vezirhan) faaliyet gösteren arıcılardan doğrudan temin edilmiştir. Bal örneklerinin toplandığ1 bölgeleri gösteren bir harita da Şekil 1'de verilmiştir. Laboratuvara ulaştırılan ballar analiz edilinceye kadar 1sı, 1şı ve nem açısından uygun koşullarda depolanmıştır.

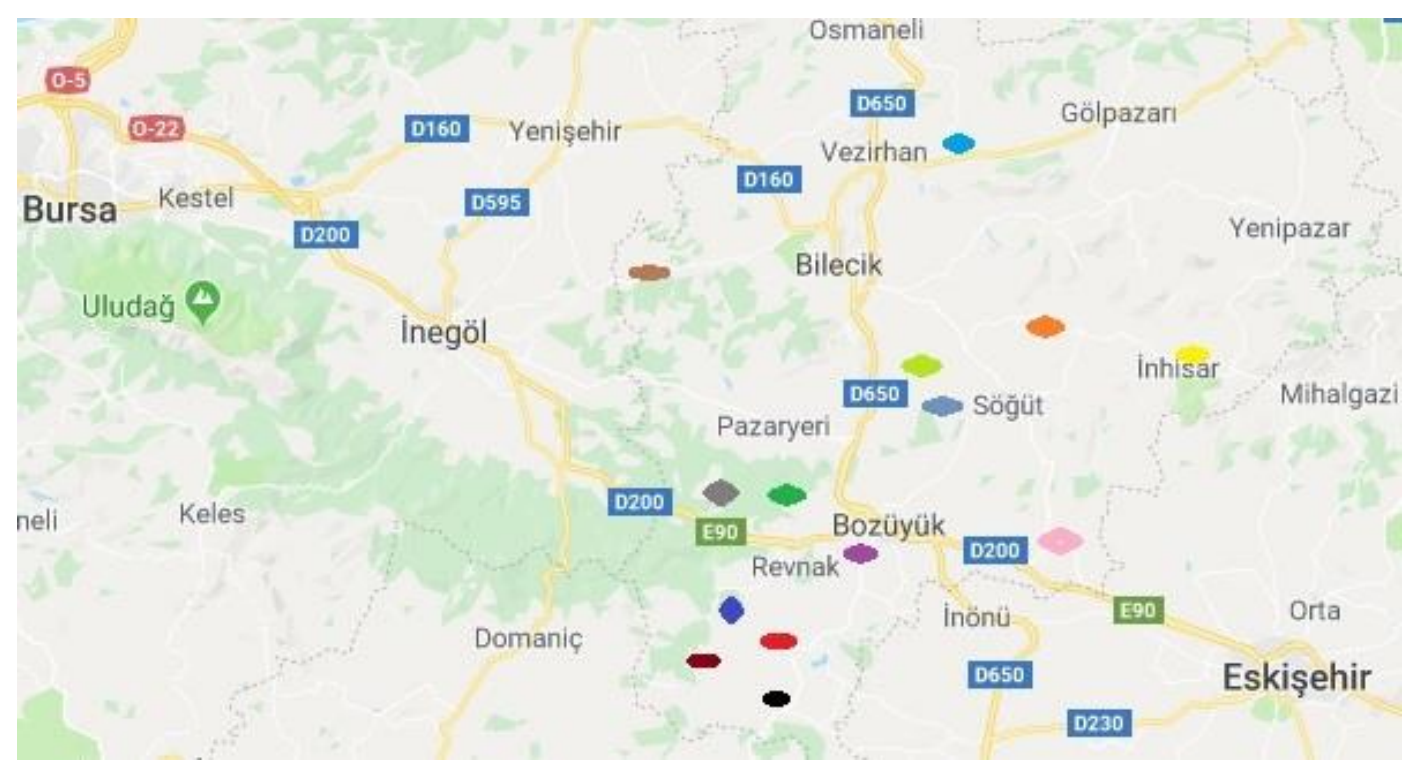

Şekil 1. Bal örneklerinin toplandığı bölgeleri gösterir harita

Figure 1. Map of the region where honey samples are collected

(Camiliyayla ODodurga Cihangazi Hamitabat İnhisar OKarasu Delielmack Vezirhan Poyra Kurtköy Erikli Saraycık Koyunköy)

\section{Melissopalinolojik analizler \\ Balların bitkisel kökenlerinin belirlenmesi}

Bal örneklerinin bitkisel kökenlerinin belirlenmesi için Moar (1985), Wodehouse (1935) ve Sorkun (2008) yöntemleri ile polen preparatlar1 hazırlanmıştır. Bunun için bal örneği cam baget yardımıyla karıştırılmış, 10 gr alınarak deney tüpüne aktarllmıştır. Üzerine $20 \mathrm{ml}$ distile su eklendikten sonra $45^{\circ} \mathrm{C}^{\prime}$ lik su banyosunda, yaklaşık 10-15 dakika bekletilerek balın su içerisinde çözünmesi sağlanmıştır. Çözelti 3500 rpm'de 45 dakika santrifüj edilmiş, süpernatant kısmı döküldükten sonra bir kurutma kağıdı üzerine ters olarak kapatılan tüplerin kurumas1 sağlanmıştır. Daha sonra bir diseksiyon iğnesi yardımıyla alınmış (yaklaşık $1-2 \mathrm{~mm}^{3}$ ) bazik fuksinli gliserol jelatin ile tüplerin dibindeki pelet bir lam üzerine aktarılmış ve 1sıtma tablasında 30$40^{\circ} \mathrm{C}$ 'de eridikten sonra $18 \times 18 \mathrm{~mm}$ 'lik lamel ile preparat haline getirilmiştir. Hazırlanan preparatlar yaklaşık 12 saat boyunca ters olarak kurutulmaya bırakılmışır. Hazırlanan polen preparatlar1 Nicon Eclipse E 400 marka 1ş1k mikroskobu ile incelenmiştir. Alanda minimum 200 polen sayılmış, botanik orijinlerin belirlenmesi için referans preparatlar ve literatürdeki kataloglardan yararlanılmıştır (Sorkun, 2008; Özkök vd., 2018; D’albore, 1997). Tanımlanan polenlerin yüzdeleri alınarak dominant ( $\geq \% 45)$, sekonder (\%16-44), minör $(\% 3-15)$ ve eser $(<\% 3)$ olarak sinıflandırılmıstır (Sorkun, 2008).

\section{Toplam polen saysinin (TPS-10) belirlenmesi}

Toplanan bal örneklerinde toplam polen sayıs1 (TPS-10), Moar (1985) ve Sorkun (2008)'a göre hazırlanmıştır. Bunun için bal örnekleri cam baget yardımıyla karıştırıldıktan sonra $10 \mathrm{~g}$ alınarak bir deney tüpüne aktarılmış, $20 \mathrm{ml}$ distile su ve şahit 
olarak da içerisinde 9666 tane Lycopodium sp. sporu olan tablet eklenmiş ve $45^{\circ} \mathrm{C}$ 'lik su banyosunda yaklaşı 10-15 dakika bekletilerek tablet ve balın su içerisinde çözünmesi sağlanmıştır. Tablet eriyip homojen bir çözelti elde edildikten sonra içerisine 10 damla bazik fuksin ilave edilmiş ve 3500 rpm'de 45 dakika santrifüj edilmiştir. Santrifüj sonrasinda süpernatant kısmı dökülen tüpler bir kurutma kağıdı üzerine ters olarak kapatılmıştır. Dip kısminda kalan peletin üzerine $0.1 \mathrm{ml} \% 50^{\prime}$ lik gliserol/su (v/v) ilave edilerek homojen bir şekilde karışması sağlanmıştır. Bu karışımdan 0.01 $\mathrm{ml}$ alınarak, $0.09 \mathrm{ml} \% 50$ 'lik gliserol/su (v/v) bulunan başka bir tüpe aktarılmış ve iyice karışması sağlanmıştır. Bu karışımdan da $0.01 \mathrm{ml}$ alınarak lam üzerine konulmuş, üzerine $18 \times 18$ mm'lik lamel kapatılmıştır. Hazırlanan preparatlar sol üst köşeden incelenmeye başlanıp tüm preparat taranarak içerisindeki polenler ve Lycopodium sp. sporları sayilmıştır. Elde edilen değerler hesaplanarak toplam polen sayısı aşağıda verilen formül kullanılarak hesaplanmıştır.

TPS-10 = (Sayılan polen/sayllan Lycopodium sp. sporlari) $\times 9666^{*}$

*Kullanılan Lycopodium sp. tabletinde bulunan spor say1s1

\section{Kimyasal analizler \\ Nem analizi}

Balların nem miktarı, Bogdanov (1997) ve Devillers vd. (2004)'ne göre refraktometre cihazı ile belirlenmiştir. Buna göre cam baget yardımıyla alınan $1 \mathrm{~g}$ bal örneği refraktometrenin cam bölmesine aktarılmış ve mercekli kısımdan bakılarak \% nem miktarı belirlenmiştir.

\section{Toplam fenolik madde miktarı}

Folin metodu fenolik maddelerin Folin Ciocalteu reaktifi ile renkli kompleks oluşturması esasına dayanır ve doğal ürünlerde toplam fenolik madde ölçümü için en çok kullanılan yöntemdir (Singleton ve Rossi, 1965; Singleton vd., 1999). Folin-Ciocalteu reaktifi molibdofosfotungstik heteropoliasiti $\quad\left(3 \mathrm{H}_{2} \mathrm{O}_{2} \mathrm{P}_{2} \mathrm{O}_{5} .13 \mathrm{WO}_{3} .5 \mathrm{MoO}_{3} .10\right.$ $\mathrm{H}_{2} \mathrm{O}$ ) olup bileşiğin aktif merkezinde $\mathrm{Mo}(\mathrm{VI})$ bulunur. Fenolik maddelerin folin reaktifi ile oluşturduğu mavi renkli kompleks 765 nm'de maksimum absorbansa sahiptir. $\mathrm{Bu}$ rengin spektrofotometrik ölçümü ile toplam fenolik madde miktar1 tespit edilir.

$\mathrm{Mo}(\mathrm{VI})_{(\text {sari) }}+\mathrm{e}_{\text {(antioksidan) }} \rightarrow \mathrm{Mo}(\mathrm{V})_{(\text {mavi) }}$

Toplam fenolik madde analizinde her bir bal örneğinden $5 \mathrm{~g}$ tartılarak $25 \mathrm{~mL}$ metanol ile 24 saat ekstraksiyonu takiben Whatman No:1 filtre kağıdından süzülen ekstraktlar kullanılmıştır. Analiz için $20 \mu \mathrm{L}$ numune (standart veya bal örneği) $680 \mu \mathrm{L}$ saf su içeren deney tüpüne ilave edilmiştir. Daha sonra bu karışıma $400 \mu \mathrm{L} 0.5 \mathrm{~N}$ folin reaktifi eklenmiş ve vorteks ile karıştırılmıştır. Ardından karışımın üzerine $400 \mu \mathrm{L}$ $\% 10$ 'luk sodyum karbonat çözeltisi ilave edilerek vorteks ile karıştırılmıştır. $30 \mathrm{dk}$ karanlıkta bekletilen örneklerin absorbanslar1 765 nm'de okunmuştur. Standart fenolik bileşik olarak gallik asit (GA) kullanılarak kalibrasyon grafiği hazırlanmıştır (Slinkard vd., 1977; Singleton ve Rossi, 1965). Gallik asitin farklı konsantrasyonlarda $(1.0 ; 0.5 ; 0.25 ; 0.125 ; 0.0625$ ve $0.03125 \mathrm{mg} \mathrm{mL}^{-1}$ ) metanol çözeltilerine karşıll1k ölçülen absorbans değerleri ile gallik asit standart grafiği çizilmiştir. Çizilen grafiğe göre ekstrakların toplam fenolik madde miktarı hesaplanmış ve sonuçlar mg GAE $\mathrm{mL}^{-1}$ cinsinden ifade edilmiştir

\section{Yüksek performansli sivi kromatografi} (HPLC) ile şeker analizi

Yüksek oranlardaki şeker içeriğinden dolayı balın şeker profili, farklı türlerdeki balların ayrımında uygun kalite kriterlerinden biridir. Buna bağlı olarak, bu çalışmada baldaki şeker içeriğinin (fruktoz ve glukoz) ve oranlarının tespiti Uluslararası Bal Komisyonu'nun (Bogdanov, 2002) belirlediği yöntem dahilinde Yüksek Performanslı Siv1 Kromatografisi (HPLC, Agilent Technologies 1200 Series, Germany) ve karbonhidrat kolonu (Agilent Technologies, Carbonhydrate $(5 \mu \mathrm{m}, 4.6 \times 250 \mathrm{~mm})$, USA) kullanılarak yapılmıştır. Buna göre; 5 gram bal örneğinin cam bir beher içerisinde tartılarak $40 \mathrm{ml}$ distile suda çözünmesi sağlanmıştır. Çözelti içerisine $25 \mathrm{ml}$ metanol eklenmiş, iyice karıştırıldıktan sonra distile su ile 100 ml'ye tamamlanmıştır. Tüm örnekler $0.45 \mu$ m'lik filtrelerden geçirilerek akış hızı $1.3 \mathrm{ml} / \mathrm{dak}$, kolon sicaklığ $30{ }^{\circ} \mathrm{C}$, enjeksiyon hacmi $50 \mu \mathrm{L}$ ve asetonitril/su oranı $80 \mathrm{ml}: 20 \mathrm{ml}$ olan hareketli 
fazdaki HPLC cihazına enjekte edilmiştir. Standart olarak fruktoz ve glikoz kullanılmıştır. Şekerlerin nicel tayini için standart çözeltiden elde edilen kromatogramdaki ilgili şeker türüne karşıllık gelen piklerin alanları standart konsantrasyonuna göre ayrı ayrı grafiğe geçirilmiştir. Numune kromatogramlarındaki pik alanları ilgili şekerler için ayrı ayrı hesaplanmıştır. Elde edilen değerler standart grafikleri ile karşılaştırılarak örneklerin şeker içerikleri hesaplanmıştır.

Gaz kromatografi-kütle spektrometresi (GCMS) ile uçucu bileşen ve yağ asitlerinin belirlenmesi

GC-MS ile uçucu bileşen ve yağ asidi analizi, Barcarolo vd., (1998); Radovic vd., (2001); Soria vd., (2003); Cuevas-Glory vd., (2007) metotlarında değişiklikler yapılarak uyarlanmıştır. Buna göre; cam bir tüpe alınan 5 gr bal örneği üzerine $25 \mathrm{ml}$ metanol ilave edilmiş, vorteks yardımıyla homojen olana kadar karıştırılmıştır. Bu karışım 3500 rpm'de 45 dakika santrifüj edildikten sonra süpernatant kısm1 $45 \mu \mathrm{m}$ 'lik por çapına sahip filtreden geçirilerek $1 \mu$ l'lik miktar GC-MS cihazına enjekte edilmiştir. Agilent marka 5973N Seçimli Kütle Dedektörlü, 6890N Network GC Sistemi (GC-MS) kullanılarak analiz yapılmıştır. DB 5MS kolon $(30 \mathrm{~m} \times 25 \mathrm{~mm}$ ve $0.25 \mu \mathrm{m}$ film kalınlığ1) kullanılmıştır. Gaz kromatografisi kısminda sicaklık, 1 dakika 50 ${ }^{\circ} \mathrm{C}$ 'de tutulduktan sonra $10{ }^{\circ} \mathrm{C} /$ dak artış hızı ile $150{ }^{\circ} \mathrm{C}$ 'ye yükseltilmiş ve bu periyottan sonra bu sıcaklıkta 2 dakika tutulmuştur. Son olarak sıcaklık dakikada $20{ }^{\circ} \mathrm{C} /$ dak artış hızı ile $280{ }^{\circ} \mathrm{C}$ ye yükseltilmiş, enjeksiyon sıcaklığ $280{ }^{\circ} \mathrm{C}$ ve analiz süresi 49.5 dakika olarak belirlenmiştir. Sonuçlar standart Wiley ve Nist Kütüphaneleri ile belirlenerek \% olarak değerlendirilmiştir (Mayda vd., 2018).

\section{SONUÇ VE TARTIŞMA}

\section{Melissopalinolojik analiz sonuçları}

Melissopalinolojik analiz sonuçları Çizelge 1 ve Şekil 2'de belirtilmiştir. Bal içerisinde bulunan toplam polen sayısı balın kalitesini belirlemek açısından önem taşımaktadır. Ballar FellerDemalsy vd. (1989) tarafindan toplam polen sayılarına göre sınıflandırılmıştır. Buna göre toplam polen saysis 20.000 'den az olan ballar düşük kaliteli; 20.000 ile 100.000 arası normal kalitede; 100.000 ile 500.000 aras1 çeşitlilik açısından zengin ballar; 500.000 ile 1.000 .000 arası çok zengin ballar; 1.000.000'dan fazla olanlar ise katkılı ballar olarak sınıflandırılmıştır. Yapılan melissopalinolojik analizler sonucunda Bilecik ilinden elde edilen ballarda 20 familyaya ait 35 farklı bitki taksonu tespit edilmiştir. Genellikle karışık çiçek balı özelliğine sahip olan ballardan B2, B6, B15, B16 numaralı örnekler dominant olarak Fabaceae (Baklagiller) familyasına ait bitki polenlerini içermektedir. B9, B11 ve B13 numaralı ballarda ise çam ballarında yoğun olarak bulunan balçiği elementlerine az miktarlarda rastlanmıştır. $\mathrm{Bu}$ durum kovanların gezgin arıcılıkla çam balı üretimi yapılan bir bölgeye taşınmış olabileceğini düşündürmüş olup gezginci arıcilığın bölge ballarında coğrafi işareti ne kadar etkilediğini göstermektedir. $\mathrm{Bu}$ nedenle sabit arıc1lı bölge ballarının coğrafi işaret değerlerinin korunması açısından oldukça önemlidir. Bilecik ilinden elde edilen balların botanik orijinleri genel olarak değerlendirildiğinde sekonder olarak Fabaceae (\%40.80), minör olarak Asteraceae, Boraginaceae, Brassicaceae, Cistaceae, Liliaceae, Poaceae, Rosaceae, Salicaceae familyalarına ait polenleri içerdiği, geri kalan familyaların ise eser miktarlarda bulunduğu görülmüştür. Bilecik floras1 Asteraceae, Brassicaceae, Fabaceae, Lamiaceae, Caryophyllaceae ve Poaceae familyaları açısından zengin olmakla birlikte (Ocak vd., 2017) bal örneklerinde Fabaceae familyasina ait polenlerin baskın olarak bulunması bu familyaya ait türlerin çiçeklenme dönemleri ile ilişkili olabileceğini düşündürmüştür. Bilecik ili genelinde ana nektar akımı dönemi Mayıs-Temmuz ayları arasındadır ve koloniler bu aylarda topladığ1 nektarı bala dönüştürmektedir. Bilecik ilinde bulunan Fabaceae familyasına ait türlerin çoğunun MayısTemmuz aralığında çiçeklendiği bildirilmektedir (Ocak vd., 2017). Toplam polen sayısı açısından değerlendirildiğinde ise ballardan 6 tanesi (B4, B5, B6, B10, B13, B14) normal kalitede, diğerleri ise düşük kalitededir. 
Çizelge 1. Bilecik ilinden toplanan balların melissopalinolojik analiz sonuçları Table 1. Melissopalynologic analysesrResults of honey samples collected from Bilecike city

\begin{tabular}{|c|c|c|c|c|c|}
\hline $\begin{array}{l}\text { Bal Örneği } \\
\text { Honey } \\
\text { samples }\end{array}$ & $\begin{array}{l}\text { Toplam } \\
\text { Polen } \\
\text { Say1s1 } \\
\text { (TPS-10) } \\
\text { Total pollen } \\
\text { number }\end{array}$ & $\begin{array}{l}\text { Dominant } \\
\text { Polenler } \\
(\geq \% 45) \\
\text { Dominant } \\
\text { Pollens }\end{array}$ & $\begin{array}{c}\text { Sekonder Polenler } \\
(\% 16-\% 45) \\
\text { Seconder Pollens }\end{array}$ & $\begin{array}{l}\text { Eser Polenler } \\
\quad(\% 3-\% 15) \\
\text { Minor Pollens }\end{array}$ & $\begin{array}{c}\text { Balın özelliği } \\
\text { Properties of Honey }\end{array}$ \\
\hline B1 & 3295 & - & $\begin{array}{l}\text { Fabaceae }(\% 21.43) \\
\text { Rosaceae }(\% 21.43)\end{array}$ & $\begin{array}{c}\text { Onobrychis sp. (Fabaceae) }(\% 14.29) \\
\text { Asteraceae }(\% 7.14) \\
\text { Boraginaceae }(\% 7.14) \\
\text { Hedysarum sp. (Fabaceae) }(\% 7.14) \\
\text { Papaveraceae }(\% 7.14) \\
\text { Poaceae }(\% 7.14) \\
\text { Salix sp. (Salicaceae) }(\% 7.14) \\
\end{array}$ & $\begin{array}{l}\text { Karışık çiçek balı/ Mix } \\
\text { blossom honey }\end{array}$ \\
\hline B2 & 5790 & $\begin{array}{c}\text { Coronilla sp. } \\
\text { (Fabaceae) } \\
(\% 63.34)\end{array}$ & $\begin{array}{c}\text { Hypericum sp. } \\
\text { (Hypericaceae) } \\
(\% 27.27)\end{array}$ & Rosaceae $(\% 9.09)$ & $\begin{array}{c}\text { Dominant olarak } \\
\text { Fabaceae Familyasına } \\
\text { ait Coronilla sp. } \\
\text { polenlerini içeriyor / } \\
\text { contains dominantly } \\
\text { Coronila sp. pollens } \\
\text { belonging to Fabaceae } \\
\text { family } \\
\end{array}$ \\
\hline B3 & 2416 & - & $\begin{array}{c}\text { Coronilla sp. } \\
\text { (Fabaceae) }(\% 33.3)\end{array}$ & $\begin{array}{c}\text { Brassicaceae }(\% 16.67) \\
\text { Trifolium sp. (Fabaceae) }(\% 16.67) \\
\text { Liliaceae }(\% 16.67) \\
\text { Rosaceae }(\% 16.67) \\
\end{array}$ & $\begin{array}{l}\text { Karışık çiçek balı/ Mix } \\
\text { blossom honey }\end{array}$ \\
\hline B4 & 20891 & - & $\begin{array}{c}\text { Fabaceae }(\% 23.08) \\
\text { Echium sp. } \\
\text { (Boraginaceae) } \\
(\% 19.23)\end{array}$ & $\begin{array}{c}\text { Cistaceae }(\% 13.46) \\
\text { Liliaceae }(\% 9.62) \\
\text { Hypericum sp. (Hypericaceae)(5.77) } \\
\text { Salix sp. (Salicaceae) }(\% 5.77)\end{array}$ & $\begin{array}{l}\text { Karışık çiçek balı/ Mix } \\
\text { blossom honey }\end{array}$ \\
\hline B5 & 20137 & - & $\begin{array}{l}\text { Fabaceae }(\% 37.04) \\
\text { Cistaceae }(\% 18.52)\end{array}$ & $\begin{array}{c}\text { Brassicaceae }(\% 14.81) \\
\text { Hypericum sp. (Hypericaeae) }(\% 14.81) \\
\text { Echium sp. (Boraginaceae) }(\% 3.70) \\
\text { Salix sp. (Salicaceae) }(\% 3.70) \\
\text { Thymus sp. (Lamiaceae) } \\
(\% 7.14) \\
\end{array}$ & $\begin{array}{l}\text { Karışık çiçek balı/ Mix } \\
\text { blossom honey }\end{array}$ \\
\hline B6 & 28736 & $\begin{array}{l}\text { Fabaceae } \\
(\% 62.86)\end{array}$ & - & $\begin{array}{l}\text { Lamiaceae }(\% 10) \\
\text { Echium sp. (Boraginaceae) }(\% 8.57) \\
\text { Centaurea sp. (Asteraceae) }(\% 5.71)\end{array}$ & $\begin{array}{c}\text { Dominant olarak } \\
\text { Fabaceae Familyasına } \\
\text { ait bitki polenlerini } \\
\text { içeriyor/ contains } \\
\text { dominantly pollens of } \\
\text { Fabaceae family }\end{array}$ \\
\hline B7 & 3493 & - & $\begin{array}{c}\text { Fabaceae }(\% 38.46) \\
\text { Coronilla } \mathrm{sp} . \\
\text { (Fabaceae) } \\
(\% 23.08)\end{array}$ & $\begin{array}{c}\text { Echium sp. (Boraginaceae) (\%7.69) } \\
\text { Cistaceae }(\% 7.69) \\
\text { Onobrychis sp. (Fabaceae) }(\% 7.69) \\
\text { Liliaceae }(\% 7.69) \\
\text { Salix sp. (Salicaceae) }(\% 7.69)\end{array}$ & $\begin{array}{l}\text { Karışık çiçek balı/ Mix } \\
\text { blossom honey }\end{array}$ \\
\hline B8 & 18411 & - & $\begin{array}{c}\text { Brassicaceae } \\
(\% 26.32) \\
\text { Fabaceae }(\% 26.32)\end{array}$ & $\begin{array}{c}\text { Asteraceae }(\% 10.53) \\
\text { Centaurea sp. (Asteraceae) }(\% 7.89) \\
\text { Salix sp. (Salicaceae) }(\% 7.89) \\
\text { Cistaceae }(\% 5.26) \\
\text { Papaveraceae }(\% 5.26) \\
\text { Poaceae }(\% 5.26)\end{array}$ & $\begin{array}{l}\text { Karışık çiçek balı/ Mix } \\
\text { blossom honey }\end{array}$ \\
\hline B9 & 19332 & - & $\begin{array}{c}\text { Brassicaceae } \\
(\% 15.22)\end{array}$ & $\begin{array}{c}\text { Fabaceae (\%14.49) } \\
\text { Poaceae (\%13.77) } \\
\text { Centaurea aggregata (Asteraceae) }(\% 11.59) \\
\text { Cistaceae }(\% 10.14) \\
\text { Asteraceae }(\% 8.70) \\
\text { Echium sp. (Boraginaceae) }(\% 5.07) \\
\text { Liliaceae }(\% 5.07) \\
\text { Coronilla sp. (Fabaceae) }(\% 5.80)\end{array}$ & $\begin{array}{l}\text { Karışık çiçek balı, } \\
\text { Balçiği Elementleri } \\
\text { (BÇE) içeriyor/ Mix } \\
\text { blossom honey, } \\
\text { contains trace amount } \\
\text { of pine honey mark }\end{array}$ \\
\hline
\end{tabular}


Çizelge 1. devam

Table 1. continuation

\begin{tabular}{|c|c|c|c|c|c|}
\hline $\begin{array}{l}\text { Bal Örneği } \\
\text { Honey } \\
\text { samples }\end{array}$ & $\begin{array}{l}\text { Toplam } \\
\text { Polen } \\
\text { Sayis1 } \\
\text { (TPS-10) } \\
\text { Total pollen } \\
\text { number }\end{array}$ & $\begin{array}{l}\text { Dominant } \\
\text { Polenler } \\
(\geq \% 45) \\
\text { Dominant } \\
\text { Pollens }\end{array}$ & $\begin{array}{c}\text { Sekonder Polenler } \\
(\% 16-\% 45) \\
\text { Seconder Pollens }\end{array}$ & $\begin{array}{l}\text { Eser Polenler } \\
(\% 3-\% 15) \\
\text { Minor Pollens }\end{array}$ & $\begin{array}{c}\text { Balın özelliği } \\
\text { Properties of Honey }\end{array}$ \\
\hline B10 & 92632 & - & $\begin{array}{l}\text { Fabaceae }(\% 32.37) \\
\text { Cistaceae }(\% 30.22)\end{array}$ & $\begin{array}{c}\text { Salix sp. (Salicaceae) (\%12.23) } \\
\text { Onobrychis sp. (Fabaceae) }(\% 7.19) \\
\text { Brassicaceae }(\% 5.04) \\
\text { Centaurea triumfetti (Asteraceae) }(\% 4.32)\end{array}$ & $\begin{array}{l}\text { Karışık çiçek balı/ Mix } \\
\text { blossom honey }\end{array}$ \\
\hline B11 & 8882 & - & $\begin{array}{l}\text { Fabaceae }(\% 23.81) \\
\text { Rosaceae }(\% 23.81)\end{array}$ & $\begin{array}{c}\text { Brassicaceae (\%14.29) } \\
\text { Trifolium pratense (Fabaceae) }(\% 14.29) \\
\text { Ranunculaceae }(\% 14.29) \\
\text { Apiaceae }(\% 4.76) \\
\text { Asteraceae }(\% 4.76)\end{array}$ & $\begin{array}{l}\text { Karışı çiçek balı, } \\
\text { Balçiği Elementleri } \\
\text { (BÇE) içeriyor/ Mix } \\
\text { blossom honey, } \\
\text { contains trace amount } \\
\text { of pine honey mark }\end{array}$ \\
\hline B12 & 3717 & - & $\begin{array}{c}\text { Salix sp. } \\
\text { (Salicaceae) } \\
(\% 42.86) \\
\text { Fabaceae }(\% 35.71) \\
\end{array}$ & $\begin{array}{c}\text { Trifolium pratense (Fabaceae) }(\% 10.71) \\
\text { Asteraceae }(\% 3.57) \\
\text { Berberidaceae }(\% 3.57) \\
\text { Papaveraceae }(\% 3.57) \\
\end{array}$ & $\begin{array}{c}\text { Karışık çiçek balı/ Mix } \\
\text { blossom honey }\end{array}$ \\
\hline B13 & 20688 & - & $\begin{array}{c}\text { Rosaceae }(\% 34.92) \\
\text { Onobrychis sp. } \\
\text { (Fabaceae) } \\
(\% 17.46)\end{array}$ & $\begin{array}{c}\text { Cistaceae }(\% 14.29) \\
\text { Salix sp. (Salicaceae) }(\% 6.35) \\
\text { Liliaceae }(\% 4.76)\end{array}$ & $\begin{array}{c}\text { Karışı çiçek balı, } \\
\text { Balçiği Elementleri } \\
\text { (BÇE) içeriyor/ Mix } \\
\text { blossom honey, } \\
\text { contains trace amount } \\
\text { of pine honey mark }\end{array}$ \\
\hline B14 & 24098 & - & Fabaceae $(\% 20.37)$ & $\begin{array}{c}\text { Onobrychis sp. (Fabaceae) (\%13.89) } \\
\text { Liliaceae }(\% 12.96) \\
\text { Coronilla sp. (Fabaceae) }(\% 9.26) \\
\text { Centaurea aggregata (Asteraceae) }(\% 8.33) \\
\text { Rosaceae }(\% 7.41) \\
\text { Anthemis sp. (Asteraceae) }(\% 6.48) \\
\text { Asteraceae }(\% 5.56) \\
\text { Salix sp. (Salicaceae) }(\% 3.70)\end{array}$ & $\begin{array}{l}\text { Karışık çiçek balı/ Mix } \\
\text { blossom honey }\end{array}$ \\
\hline B15 & 11316 & $\begin{array}{l}\text { Fabaceae } \\
(\% 47.37)\end{array}$ & $\begin{array}{l}\text { Cisteceae }(\% 21.05) \\
\text { Geraniaceae } \\
(\% 15.79)\end{array}$ & $\begin{array}{c}\text { Echium sp. (Boraginaceae) }(\% 5.26) \\
\text { Rosaceae }(\% 5.26) \\
\text { Salix sp. (Salicaceae) }(\% 5.26)\end{array}$ & $\begin{array}{c}\text { Dominant olarak } \\
\text { Fabaceae Familyasina } \\
\text { ait bitki polenlerini } \\
\text { içeriyor }\end{array}$ \\
\hline B16 & 3866 & $\begin{array}{c}\text { Coronilla sp. } \\
\text { (Fabaceae) } \\
(\% 55.17)\end{array}$ & $\begin{array}{l}\text { Trifolium pratense } \\
\text { (Fabaceae) } \\
(\% 20.69)\end{array}$ & $\begin{array}{c}\text { Centaureae aggregata (Asteraceae) } \\
(\% 10.34) \\
\text { Asteraceae }(\% 6.90) \\
\text { Apiaceae }(\% 3.45) \\
\text { Brassicaceae }(\% 3.45)\end{array}$ & $\begin{array}{c}\text { Dominant olarak } \\
\text { Fabaceae Familyasina } \\
\text { ait Coronilla sp. } \\
\text { polenlerini içeriyor/ } \\
\text { contains dominantly } \\
\text { Coronila sp. pollens } \\
\text { belonging to Fabaceae } \\
\text { family }\end{array}$ \\
\hline
\end{tabular}

\section{Kimyasal analiz sonuçları}

\section{Nem analizi sonuçlart}

Uluslararasi Bal Kodeksi (Anonymous, 2001) ve Türk Gida Kodeksi Bal Tebliği (2012)'ne göre ballardaki nem oranı en fazla \%20 olmalıdır. Ballardaki nem oranı bu değerin üzerine çıktığında patojen mikroorganizmalar üreyecek ve sağlık açısından olumsuz sonuçlara sebep olabilecektir (Singh and Singh, 2018). Yapılan çalışmada balların nem içerikleri \%15.8 (B1) ile \%19.5 (B15) arasında değişmekle birlikte ortalama $\% 17.38 \pm 0.85$ olarak belirlenmiştir (Çizelge 2).
Elde edilen değerler kodeks ve tebliğ limitleri ile uyumludur.

\section{Toplam fenolik madde miktarn}

Örneklerin toplam fenolik madde miktarları gallik ait eşdeğeri (GAE) olarak hesaplanmıştır ve Şekil 3 'te verilmiştir. Bal örneklerinin fenolik içerikleri en düşük Erikli bal örneğinde 33 mg GAE/100 g ve en yüksek Koyunköy bal örneğinde $81 \mathrm{mg}$ GAE/100 g olarak belirlenmiştir. Toplam fenolik içeriği balın floral zenginliği ile doğrudan ilişkili olup balın antioksidan kapasitesinden de 
sorumludur. Gül ve Pehlivan (2018) tarafindan yapılan bir çalışmada Türkiye'nin farklı bölgelerinden toplanan bal örneklerinin toplam fenolik madde miktarlarının 34.37-470.70 $\mathrm{mg} / 100 \mathrm{~g}$ GAE aralığında olduğu belirlenmiştir. Kolaylı vd. (2008) tarafindan yapılan bir çalışmada ise üç farklı bal türü (Kestane, Anzer ve karışık çiçek) antioksidan kapasiteleri açısından karşılaştırılmıştır. Üç bal türünün toplam fenolik madde miktarlarının sirasiyla 430.68, 240.52 ve $170.35 \mathrm{mg}$ GAE/100 g olarak belirlendiği bildirilmiştir. Sagdic vd. (2013) tarafindan farklı sayıda kestane, çam, karışık çiçek, kekik ve keven balları ile yapılan bir çalışmada da karışık çiçek ballarının fenolik madde miktarlarının 5.09 ile $32.76 \mathrm{mg}$ GAE/100 g aralığında değiştiği belirlenmiştir. Güzel ve Bahçeci (2019) Çorum yöresinden topladıkları bal örneklerinin toplam fenolik madde miktarlarının 24.3-54.6 mg GAE/ $100 \mathrm{~g}$ aralı̆̆ında değisstiğini ifade etmişlerdir.
Çalışmamızda analiz edilen Bilecik iline ait ballarının toplam fenolik madde miktarlarının literatür verileri ile uyumlu olduğu görülmektedir. Balların toplam fenolik madde içerikleri ile antioksidan kapasiteleri arasında doğrusal bir ilişki olduğu da yapılan çalışmalarda vurgulanmıştır (Gül ve Pehlivan, 2018).

\section{HPLC ile şeker analizi}

Ballara ait şeker analizi sonuçları Çizelge 2'de verilmiştir. Uluslararası Bal Kodeksi (Anonymous, 2001) ve Türk Gida Kodeksi Bal Tebliği'ne (Anonymous, 2012) göre çiçek ballarında fruktoz/glukoz (F/G) oranı 0.9 ile 1.4 arasında olmalıdır. Çalışma sonuçlarına göre Bilecik ilinden toplanmış bal örneklerinin F/G oranları 0.96 ile 1.22 aralığında ortalama $1.08 \pm 0.07$ olarak belirlenmiş olup, tüm ballar tebliğe uygunluk göstermektedir.

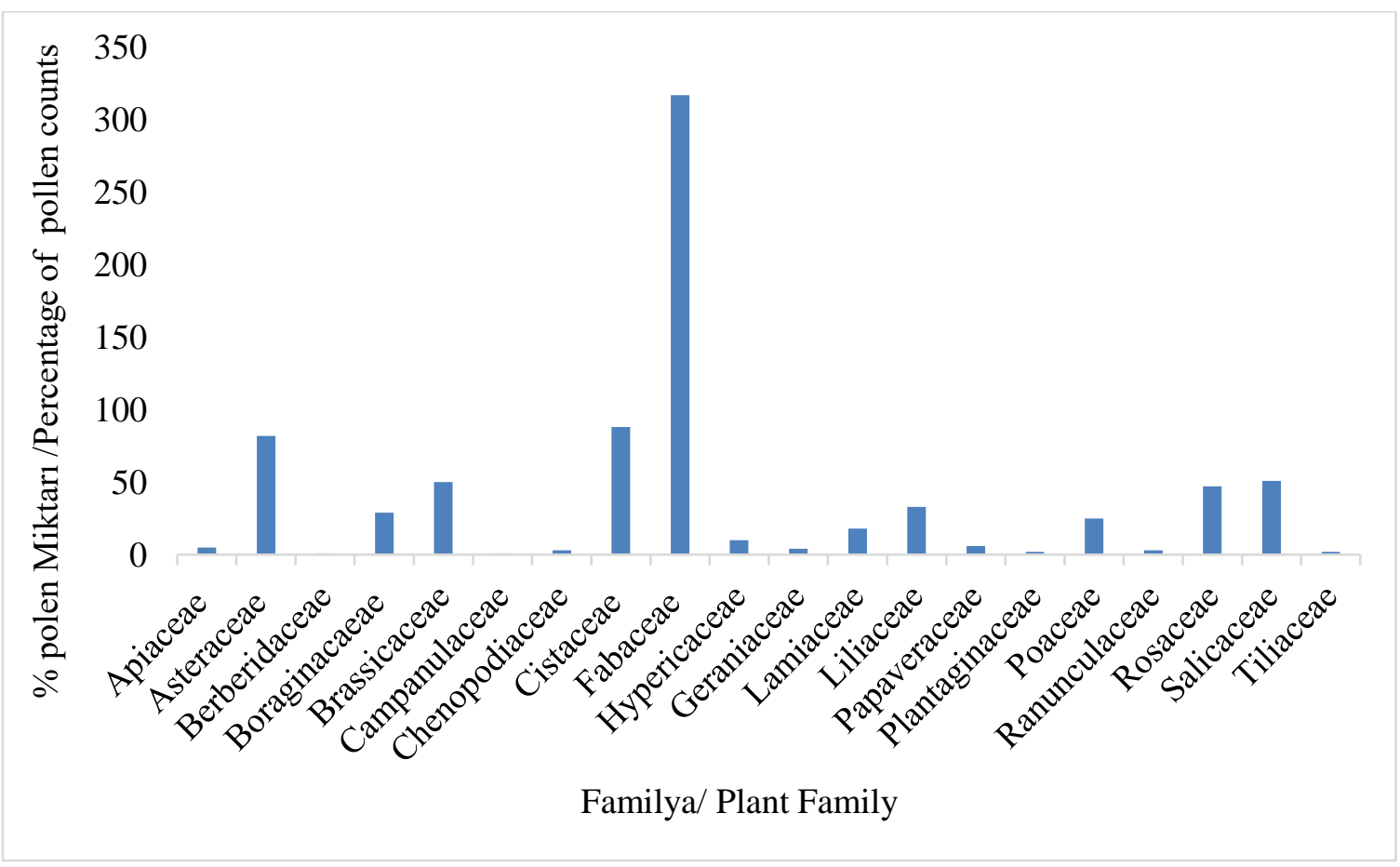

Sekil 2. Bilecik ili ballarında saptanan familyaların yoğunluğu

Figure 2. Dencity of families detected in Honey samples of Bilecike province 


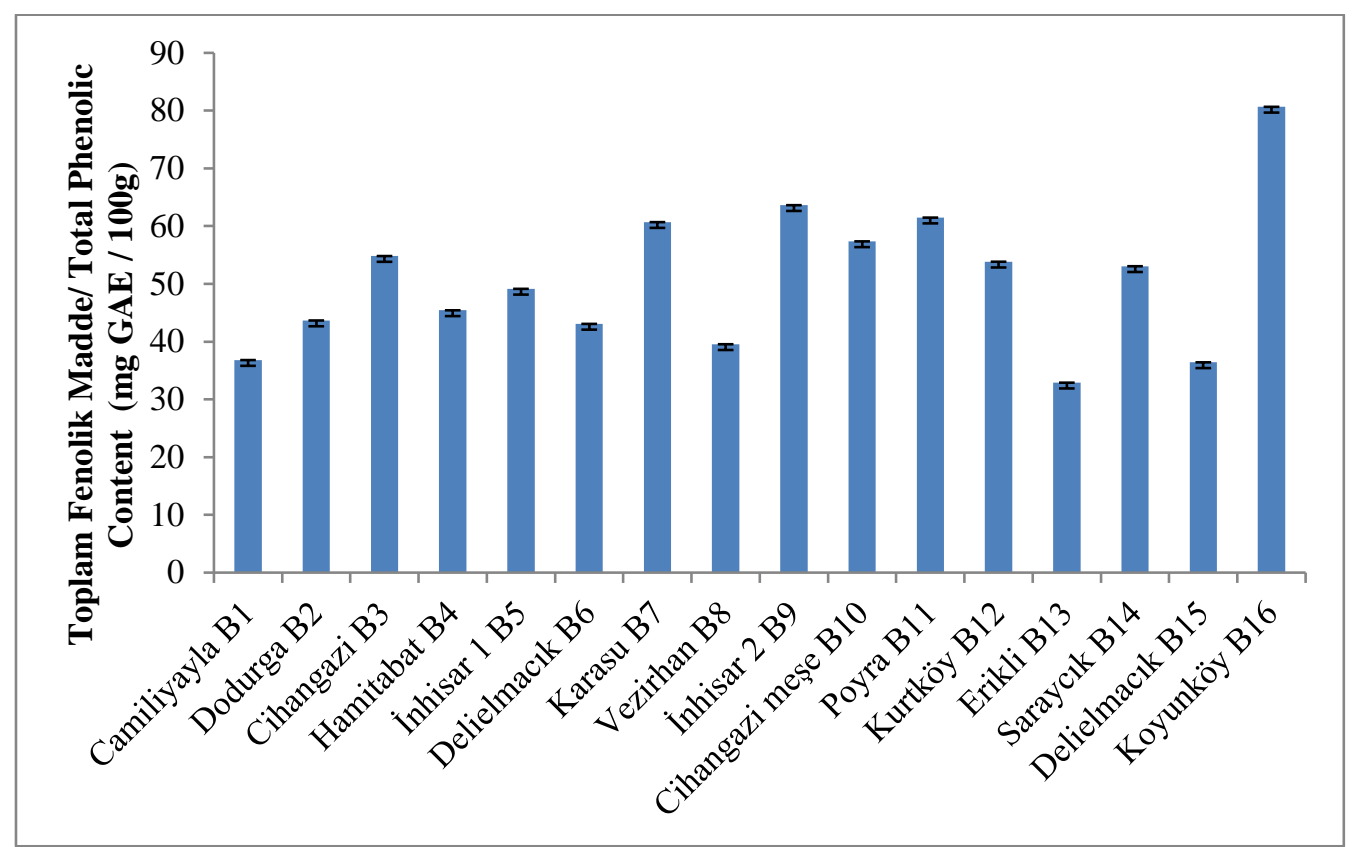

Şekil 3. Bal örneklerinin toplam fenolik madde miktarı Figure 3. Total phenolic contents of honey samples

Çizelge 2. Bilecik ilinden toplanan balların \%nem ve HPLC ile şeker analizi sonuçları Table 2. Moisture and sugar content of honey samples collected from Bilecik province

\begin{tabular}{|c|c|c|c|c|}
\hline $\begin{array}{l}\text { Bal Örneği } \\
\text { Honey sample }\end{array}$ & $\begin{array}{c}\% \mathrm{Nem} \\
\text { Moisture (\%) }\end{array}$ & $\begin{array}{c}\text { Fruktoz (F) (g) } \\
\text { Fructose (F) }(\mathrm{g})\end{array}$ & $\begin{array}{c}\text { Glukoz (G) (g) } \\
\text { Glucose }(G)(g)\end{array}$ & $\begin{array}{l}\mathrm{F} / \mathrm{G} \\
F / G\end{array}$ \\
\hline B1 & $15.8 \pm 0.95$ & $26.59 \pm 2.24$ & $24.93 \pm 2.34$ & 1.06 \\
\hline B2 & $17.7 \pm 0.84$ & $29.33 \pm 1.98$ & $26.97 \pm 1.23$ & 1.08 \\
\hline B3 & $17.2 \pm 0.99$ & $30.68 \pm 2.68$ & $26.66 \pm 1.67$ & 1.15 \\
\hline B4 & $17.4 \pm 1.12$ & $32.47 \pm 2.96$ & $31.17 \pm 2.48$ & 1.04 \\
\hline B5 & $17.5 \pm 1.18$ & $29.8 \pm 1.64$ & $27.36 \pm 1.25$ & 1.08 \\
\hline B6 & $16.5 \pm 0.83$ & $38.03 \pm 3.24$ & $35.4 \pm 2.74$ & 1.07 \\
\hline B7 & $17.2 \pm 1.32$ & $32.4 \pm 2.74$ & $26.49 \pm 1.76$ & 1.22 \\
\hline B8 & $17 \pm 1.05$ & $27.61 \pm 2.58$ & $27.35 \pm 2.34$ & 1.01 \\
\hline B9 & $17.8 \pm 1.86$ & $29.94 \pm 2.25$ & $26.21 \pm 1.88$ & 1.14 \\
\hline B10 & $18.3 \pm 2.15$ & $30.32 \pm 2.94$ & $28.65 \pm 2.04$ & 1.05 \\
\hline B11 & $17.3 \pm 1.87$ & $29.64 \pm 1.91$ & $28.86 \pm 1.28$ & 1.02 \\
\hline B12 & $17.5 \pm 0.67$ & $27.2 \pm 1.34$ & $22.78 \pm 0.93$ & 1.19 \\
\hline B13 & $16.3 \pm 1.38$ & $23.38 \pm 1.16$ & $20.57 \pm 0.89$ & 1.13 \\
\hline B14 & $17.8 \pm 1.75$ & $27.49 \pm 1.87$ & $24.86 \pm 1.12$ & 1.10 \\
\hline B15 & $19.5 \pm 2.28$ & $28.04 \pm 0.99$ & $29.17 \pm 1.14$ & 0.96 \\
\hline B16 & $17.3 \pm 1.26$ & $29.08 \pm 1.83$ & $27.12 \pm 1.46$ & 1.07 \\
\hline $\begin{array}{lr}\text { Ortalama } \pm & \text { standart } \\
\text { sapma / Mean value } \\
\text { with } \quad \text { standard } \\
\text { deviations }\end{array}$ & $17.39 \pm 1.24$ & $29.5 \pm 2.26$ & $27.15 \pm 2.75$ & 1.08 \\
\hline
\end{tabular}


Ş. Keskin, N. Mayda, M. Keskin, A. Özkök

Çizelge 3. Bilecik ilinden toplanan balların GC-MS ile uçucu bileşen ve yağ asidi analiz sonuçları Table 3. Results for volatile compound and fatty acid analyses of honey samples by GC-MS

\begin{tabular}{|c|c|c|c|c|c|c|c|c|c|c|c|c|c|c|c|c|}
\hline $\begin{array}{l}\text { BİLEŞIK GRUPLARI } \\
\text { Compound classes }\end{array}$ & B1 & B2 & B3 & B4 & B5 & B6 & B7 & B8 & B9 & B10 & B11 & B12 & B13 & B14 & B15 & B16 \\
\hline \multicolumn{17}{|l|}{ Aldehitler/Aldebydes } \\
\hline 2-Methylbutyraldehyde & - & F & 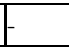 & - & - & - & - & F & F & F & 1.23 & - & {[} & 0.30 & 0.48 & 0.32 \\
\hline Butyraldehyde; butanal & - & 2.24 & 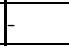 & 5 & - & - & 0.12 & - & 1.45 & 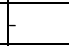 & - & - & t & 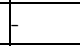 & - & - \\
\hline cis-4-Heptenal & - & - & 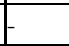 & - & - & - & - & - & 0.33 & 0.28 & - & - & 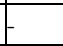 & - & 0.12 & 0.18 \\
\hline cis-6-Nonenal & - & - & 0.24 & - & 0.26 & 0.44 & 0.33 & 0.58 & 0.46 & 0.40 & 0.35 & - & 0.04 & 0.37 & 0.51 & 0.32 \\
\hline Octanal & - & - & - & - & - & - & - & - & - & 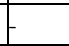 & 0.97 & - & 7 & 0.64 & - & - \\
\hline Nonanal & - & - & - & 1 & - & 0.33 & - & - & - & - & - & - & 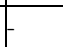 & - & - & - \\
\hline Citral & - & 0.55 & 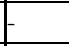 & $\Gamma$ & - & - & - & 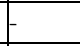 & 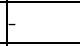 & 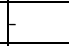 & - & - & - & 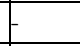 & - & - \\
\hline Isobutyraldehyde & - & 4.35 & 3.29 & 3.17 & 2.04 & 3.12 & 2.99 & - & 1.38 & 3.30 & 6.13 & 5.32 & & 1.02 & 2.80 & 2.41 \\
\hline n-decanal & - & - & - & - & - & - & 0.59 & - & 0.87 & 5 & - & 0.96 & 0.76 & - & - & - \\
\hline n-Valeraldehyde & - & 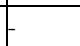 & - & - & - & 0.25 & - & 0.67 & - & F & - & - & 0.76 & - & - & - \\
\hline \begin{tabular}{|l|} 
trans.trans-2.4- \\
Hexadienal
\end{tabular} & - & - & 0.23 & & - & - & - & & ] & & & - & & - & - & - \\
\hline 2-Methyl-2-pentenal & - & 1.19 & - & - & - & - & - & 1.72 & - & . & - & - & & - & - & - \\
\hline Toplam/Total & E & 8.33 & 3.76 & 3.17 & 2.30 & 4.14 & 4.03 & 2.79 & 4.49 & 3.98 & 8.68 & 6.28 & 1.56 & 2.33 & 3.91 & 3.23 \\
\hline \multicolumn{17}{|c|}{ Alifatik Asitler ve Esterleri/Aliphatic acids and their esters } \\
\hline $\begin{array}{l}\text { 2-Methyl-2-pentanoic } \\
\text { acid }\end{array}$ & 1 & L & 0.95 & 3.25 & 0.17 & - & 0.55 & 5 & - & F & 0.15 & - & 1.31 & 0.64 & 0.25 & - \\
\hline 4-Methyloctanoic acid & - & 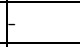 & - & - & - & - & 0.18 & - & - & f & 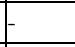 & - & & 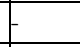 & - & 0.66 \\
\hline Heptanoic acid & & 1.16 & 1.62 & 5.03 & 0.43 & 5.12 & 2.44 & & 7.75 & 2.02 & & 2.04 & 2.29 & 1.55 & 3.31 & \\
\hline Hexanoic acid & 14.31 & 4.36 & & 2.20 & 0.55 & 1.45 & 6.42 & 4.14 & 1.53 & 3.78 & 3.50 & 0.12 & 1.40 & 3.27 & 4.19 & 0.73 \\
\hline trans-2-Hexenoic acid & - & - & - & 0.78 & - & 1.98 & - & 5 & - & 0.81 & - & - & F & - & - & - \\
\hline 3-Hexenoic acid & - & 0.02 & - & 5 & 0.07 & 0.72 & 0.69 & 0.13 & - & 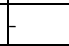 & 0.23 & 0.34 & - & - & - & 0.18 \\
\hline \begin{tabular}{|l|} 
Decanoic acid \\
\end{tabular} & 0.72 & - & - & - & - & 0.52 & - & 0.31 & - & 4.23 & - & - & - & - & - & 2.07 \\
\hline Citronellic acid & - & - & - & - & 0.11 & - & - & - & - & - & - & - & - & - & 0.32 & - \\
\hline 4-Methylpentanoic acid & 4.12 & 3.15 & 5.57 & - & 3.74 & 0.09 & 1.68 & 1.80 & - & . & 1.47 & - & - & - & - & 1.55 \\
\hline Benzoic acid & & & 0.22 & 0.29 & 2.21 & 2.32 & 0.50 & 0.19 & 3.12 & 0.93 & 0.23 & 0.90 & 0.11 & 2.41 & 1.50 & 1.89 \\
\hline Diethyl succinate & 1.80 & 0.72 & 0.43 & 0.63 & - & - & 1.37 & 5 & 1.26 & - & - & - & - & - & - & 2.02 \\
\hline Propionic acid & - & - & - & - & - & - & - & F & - & F & - & - & - & - & - & 4.48 \\
\hline Pyruvic acid & 7.13 & 16.53 & 22.79 & 26.71 & 28.65 & 30.86 & 3.66 & 47.03 & 24.29 & 9.34 & 14.22 & 35.56 & 7.73 & 42.68 & 22.70 & 8.77 \\
\hline Valeric acid & - & 1.40 & 1.64 & - & 6.97 & 0.11 & 0.36 & 1.69 & - & 0.90 & - & - & - & 1.39 & - & - \\
\hline 2-Ethylbutyl acetate & - & 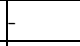 & - & - & 0.27 & - & 0.26 & 0.40 & 1.35 & 0.71 & - & 0.44 & 0.45 & 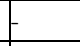 & - & - \\
\hline Ethylacetoacetate & - & 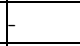 & - & - & - & - & - & - & 0.88 & . & - & - & - & - & - & 2.65 \\
\hline Heptyl butyrate & - & 0.01 & 0.02 & - & 0.02 & - & 0.03 & 0.05 & - & 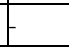 & - & - & - & - & 0.01 & - \\
\hline Hexyl acetate & 2.24 & 1.22 & 1.22 & 7 & 1.03 & - & 0.08 & 1.31 & 0.84 & 0.07 & 0.77 & 0.19 & 0.83 & 0.19 & 0.12 & 1.62 \\
\hline Isoamyl propionate & - & 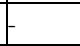 & - & 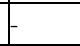 & - & 0.06 & - & - & - & - & - & - & - & - & - & - \\
\hline Isopropyl acetate & 1.85 & 1.50 & - & - & 0.18 & - & - & 0.39 & 0.82 & F & - & - & 0.47 & - & - & - \\
\hline Lauryl acetate & 6.43 & 0.49 & 0.54 & 0.53 & 2.45 & 2.26 & 0.90 & 1.01 & - & 0.05 & - & - & 0.29 & 0.14 & 0.25 & 0.48 \\
\hline n-Butyl acetate & - & 0.53 & 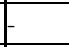 & 0.19 & - & 0.02 & - & - & 0.07 & - & - & 0.36 & - & - & - & 1.67 \\
\hline n-Propyl acetate & 1.37 & 2.55 & 3.08 & 1.94 & 1.41 & 2.61 & 1.59 & 1.86 & 1.39 & 1.92 & 1.49 & 2.85 & 1.70 & 2.76 & 1.81 & 9.33 \\
\hline 2-Methylbutylacetate & 3.47 & F & 4.88 & - & - & - & - & - & - & 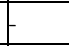 & 0.42 & - & 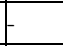 & - & - & - \\
\hline Isobutyl butyrate & - & 2.54 & 0.59 & - & - & - & 0.54 & 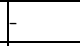 & - & F & - & - & 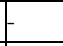 & 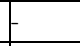 & - & - \\
\hline Ethyl acetate & - & 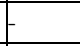 & 0.04 & 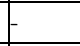 & - & - & - & 0.80 & - & 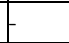 & - & - & - & - & - & - \\
\hline Ethyl-3-hexenoate & - & T & 1.32 & 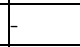 & 0.43 & - & - & - & - & 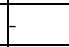 & - & - & - & - & - & - \\
\hline Methyl-2-furoate & - & 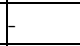 & - & 1.87 & - & - & 1.46 & 2.59 & - & - & - & - & 1.43 & & - & - \\
\hline Nonyl acetate & - & - & - & 0.12 & - & - & 0.55 & - & 0.39 & 5.56 & 0.57 & 2.11 & & - & - & - \\
\hline \begin{tabular}{|l} 
Methyl caproate \\
\end{tabular} & - & - & 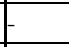 & $\frac{1}{1}$ & - & - & - & 0.26 & - & 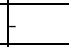 & - & - & 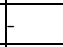 & - & - & - \\
\hline Ethyl-2methylbutyrate & F & E & 1 & 1 & F & - & - & 0.30 & $F$ & 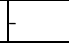 & 1 & - & $F$ & 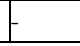 & $F$ & $F$ \\
\hline
\end{tabular}


Bilecik ballarının karakterizasyonu

Çizelge 3. devam

Table 3. continuation

\begin{tabular}{|c|c|c|c|c|c|c|c|c|c|c|c|c|c|c|c|c|}
\hline \begin{tabular}{|l|} 
BíLEŞ่̇K GRUPLARI \\
Compound classes \\
\end{tabular} & B1 & B2 & B3 & B4 & B5 & B6 & B7 & B8 & B9 & B10 & B11 & B12 & B13 & B14 & B15 & B16 \\
\hline Anisyl butyrate & - & - & - & - & - & - & - & 0.05 & F- & F & - & - & - & - & - & - \\
\hline Isobutyl propionate & - & 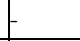 & 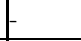 & - & - & - & - & 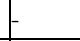 & 0.18 & 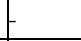 & - & - & - & - & - & - \\
\hline Isoamyl isovalerate & - & - & - & - & - & - & - & - & 0.13 & 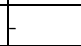 & - & - & - & - & - & - \\
\hline Propyl propionate & - & - & - & - & - & - & - & F & - & 0.10 & - & - & - & - & - & - \\
\hline Heptyl acetate & - & - & 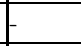 & 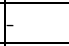 & - & - & - & - & - & 1.04 & - & - & 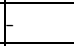 & - & - & - \\
\hline Methyl isobutyrate & - & . & - & - & - & - & - & - & - & 0.88 & 1.17 & - & - & - & 3.54 & - \\
\hline Butyl propionate & 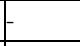 & 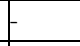 & 5 & - & - & - & - & 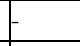 & 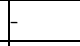 & 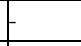 & 0.15 & - & - & - & - & - \\
\hline \begin{tabular}{|l|} 
Menthyl acetate \\
\end{tabular} & 1 & . & - & 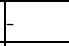 & - & - & - & 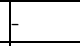 & - & 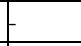 & - & - & 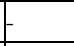 & 0.33 & - & - \\
\hline Decyl acetate & - & - & - & - & - & 1.14 & - & 0.97 & - & 0.55 & 1.08 & 0.89 & 0.07 & 0.57 & 0.76 & 2.40 \\
\hline \begin{tabular}{|l|} 
Toplam/Total \\
\end{tabular} & 43.44 & 36.18 & 44.91 & 43.54 & 48.69 & 49.26 & 23.26 & 65.28 & 44.00 & 32.89 & 25.45 & 45.80 & 18.08 & 53.93 & 38.76 & 40.50 \\
\hline \multicolumn{17}{|l|}{ Alkoller/Alcohols } \\
\hline 1-Decanol & - & F & 5 & - & - & - & 0.18 & F & F & F & F & - & - & - & - & - \\
\hline 1-octen-3-ol & 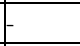 & 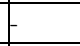 & - & 0.47 & - & 0.18 & - & 0.31 & & 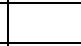 & 0.34 & - & 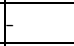 & - & - & - \\
\hline 1-Penten-3-ol & - & 0.49 & 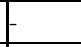 & - & 0.85 & 0.25 & - & F & 0.86 & 0.87 & - & - & - & - & - & 2.34 \\
\hline 2-Heptanol & - & 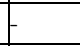 & - & - & - & - & - & - & - & . & - & - & - & - & 0.01 & 0.12 \\
\hline 2-Octanol & - & - & - & - & - & - & 22.87 & - & 13.68 & 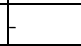 & - & - & - & - & - & - \\
\hline 3-Octanol & - & 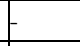 & 0.67 & 0.10 & 1.50 & - & - & 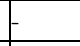 & 0.11 & 0.02 & 0.55 & 0.13 & 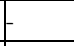 & - & - & - \\
\hline 2-Pentanol & 0.06 & 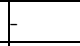 & - & 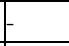 & - & - & - & 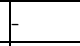 & 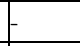 & 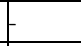 & - & - & 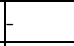 & - & - & - \\
\hline Geraniol & - & 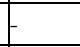 & - & - & - & - & 0.51 & - & - & 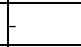 & - & - & 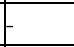 & - & - & 0.36 \\
\hline \begin{tabular}{|l|} 
alpha.alpha- \\
Dimethylphenethyl \\
alcohol
\end{tabular} & & - & 0.43 & - & 0.34 & - & - & - & - & 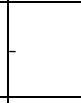 & - & - & & - & - & - \\
\hline Isopropyl alcohol & 0.41 & - & 5 & - & - & - & - & - & & 0.08 & - & - & 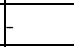 & - & - & - \\
\hline \begin{tabular}{|l|} 
isobutyl alcohol \\
\end{tabular} & 5 & 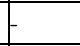 & - & 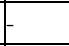 & - & - & - & - & 0.02 & 0.03 & - & - & - & - & - & - \\
\hline Amyl alcohol & - & - & - & 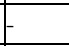 & - & - & - & - & - & 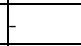 & - & - & - & 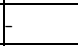 & - & 0.50 \\
\hline \begin{tabular}{|l|} 
Furfuryl alcohol \\
\end{tabular} & 0.68 & 1.05 & 2.54 & 1.20 & 2.06 & 2.25 & 1.72 & 1.61 & 2.17 & 1.73 & 2.27 & 2.02 & 1.96 & 2.15 & 0.71 & 2.49 \\
\hline Isoamyl alcohol & - & 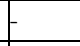 & - & - & - & - & 0.38 & 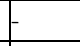 & 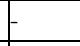 & 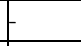 & - & - & - & - & - & - \\
\hline 3.7-Dimethyl-1-octanol & - & - & - & - & - & - & - & - & - & - & - & - & - & - & - & 0.33 \\
\hline Toplam/Total & 1.15 & 1.54 & 3.64 & 1.77 & 4.75 & 2.68 & 25.28 & 1.92 & 16.84 & 2.7 & 3.16 & 2.15 & 1.96 & 2.15 & 0.72 & 6.14 \\
\hline \multicolumn{17}{|c|}{ Hidrokarbonlar/Hydrocarbons } \\
\hline n-Tetradecane & & t & 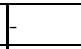 & - & - & - & 1.40 & - & - & F & - & - & - & - & - & - \\
\hline n-Undecane & 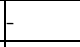 & 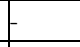 & 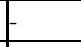 & - & - & 1.60 & - & - & - & 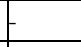 & 0.33 & - & - & - & - & - \\
\hline n-Nonane & - & - & - & - & 3.02 & - & - & 0.59 & - & . & - & - & - & 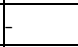 & - & - \\
\hline Pentadecane & 5 & 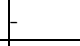 & 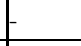 & - & 3.25 & - & 1.43 & - & - & 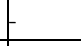 & 0.81 & - & - & - & - & - \\
\hline n-Eicosane & - & 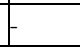 & - & - & 0.58 & - & 0.34 & - & - & 0.30 & - & - & 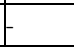 & 1.55 & - & - \\
\hline Styrene & - & - & - & - & - & - & - & - & - & 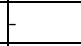 & - & - & 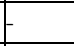 & - & - & 0.11 \\
\hline n-Tetracosane & - & 3.70 & 0.59 & - & - & - & - & 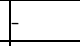 & - & 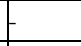 & - & - & - & - & - & 0.39 \\
\hline n-Decane & - & 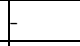 & - & 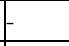 & 0.09 & - & - & - & 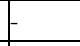 & 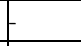 & - & - & - & - & - & - \\
\hline Toplam/Total & - & 3.70 & 0.59 & 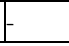 & 6.94 & 1.60 & 3.17 & 0.59 & E & F & 1.14 & - & 1 & 1.55 & - & 0.50 \\
\hline \multicolumn{17}{|l|}{ Ketonlar/Ketones } \\
\hline 2-Furyl-methylketone & & F & $T$ & 0.27 & - & - & - & 0.24 & 0.28 & F & 0.09 & 0.15 & 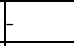 & 0.30 & 0.10 & - \\
\hline 2-Octanone & E & 0.82 & - & 0.35 & - & 0.93 & 0.39 & 0.66 & - & 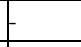 & - & - & - & 0.20 & 0.50 & 0.38 \\
\hline 2-Nonanone & - & - & 0.27 & - & - & - & - & - & - & 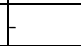 & - & - & - & 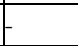 & - & - \\
\hline 2-Pentanone & E & - & 5 & 5 & - & - & - & - & - & . & - & - & - & - & - & - \\
\hline 3.4-Hexanedione & - & 0.28 & 5 & - & - & - & - & - & 0.72 & 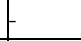 & 0.87 & - & - & - & - & - \\
\hline $\begin{array}{l}\text { 3.5-Dimethyl-1.2- } \\
\text { cyclopentadione }\end{array}$ & & & 0.48 & 0.50 & & 1.03 & 1.15 & 0.65 & 0.47 & 1.44 & 0.39 & & 0.63 & & - & 0.10 \\
\hline
\end{tabular}


Çizelge 3. devam

Table 3. continuation

\begin{tabular}{|c|c|c|c|c|c|c|c|c|c|c|c|c|c|c|c|c|}
\hline $\begin{array}{l}\text { BİLEŞIK GRUPLARI } \\
\text { Compound classes }\end{array}$ & B1 & B2 & B3 & B4 & B5 & B6 & B7 & B8 & B9 & B10 & B11 & B12 & B13 & B14 & B15 & B16 \\
\hline $\begin{array}{l}\text { 5-Methyl-2.3- } \\
\text { hexanedione }\end{array}$ & & 0.60 & & & & & & & - & & & 0.38 & & 0.07 & 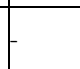 & \\
\hline $\begin{array}{l}\text { 6-Methyl-3.5-heptadien- } \\
\text { 2-one }\end{array}$ & & 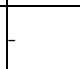 & & & 0.32 & & - & & 5 & 0.50 & & & 0.80 & 0.53 & - & \\
\hline Diacetyl & - & - & 0.38 & 0.34 & - & - & - & & - & 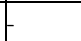 & 0.61 & - & - & 0.20 & 0.41 & - \\
\hline Homofuronol & 4.08 & 3.40 & 3.07 & 4.02 & 2.22 & 6.19 & 14.03 & 1.14 & 7.92 & 32.64 & 4.40 & 5.75 & 36.03 & 5.74 & 1.28 & 5.56 \\
\hline Methyl ethyl ketone & 1.79 & - & - & - & - & - & - & - & - & 5 & - & - & 2.19 & - & - & - \\
\hline Toplam/Total & 5.87 & 5.1 & 4.2 & 5.48 & 2.54 & 8.15 & 15.57 & 2.69 & 9.39 & 34.58 & 6.36 & 6.28 & 36.65 & 7.04 & 2.29 & 6.04 \\
\hline \multicolumn{17}{|l|}{ Terpenler/Terpenes } \\
\hline Isoborneol (isomer 1) & 2.52 & 3.78 & 3.72 & 3.03 & 3.69 & 3.12 & 4.19 & 7.43 & 3.96 & 3.69 & 2.30 & 2.56 & 3.47 & 3.33 & 4.01 & - \\
\hline Limonene & - & - & - & & 0.15 & - & - & - & - & - & - & 0.77 & 0.35 & - & 0.26 & - \\
\hline Neroloxide & 5 & 0.49 & - & 0.87 & - & - & 0.13 & & - & 0.27 & - & 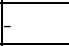 & - & 1 & - & 0.44 \\
\hline Menthone & - & - & - & - & - & - & F & 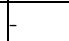 & - & 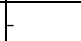 & 0.10 & - & - & - & - & - \\
\hline $\begin{array}{l}\text { Linaloxide (trans. isomer } \\
\text { A) }\end{array}$ & & - & - & - & - & - & - & 1.31 & - & 0.57 & - & & - & & - & - \\
\hline Farnesol & - & - & - & - & - & 0.11 & - & 5 & - & 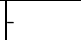 & - & - & - & & - & - \\
\hline Toplam/Total & 2.52 & 4.27 & 3.72 & 3.9 & 3.84 & 3.23 & 4.32 & 8.74 & 3.96 & 4.53 & 2.40 & 3.33 & 3.82 & 3.33 & 4.27 & 0.44 \\
\hline \multicolumn{17}{|l|}{ Yağ asitleri/Fatty Acids } \\
\hline Isovaleric acid & - & - & - & 0.09 & & - & - & I & 1.13 & 1.06 & 1.40 & F & 0.19 & - & $F$ & $F$ \\
\hline Lauric acid & - & 1.50 & 7 & 0.03 & 1.03 & - & - & - & - & 5 & 3.96 & - & - & 0.03 & 0.02 & 2.71 \\
\hline Myristic acid & 0.27 & - & 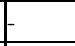 & 0.68 & 1.97 & 0.61 & E & 0.36 & 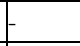 & 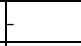 & 2.54 & 3.25 & 7.87 & 0.87 & 1.49 & 4.76 \\
\hline Butyric acid & $f$ & 0.17 & $t$ & - & 1.62 & - & - & - & - & 0.16 & 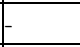 & - & 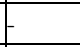 & 0.09 & 0.54 & - \\
\hline Nonanoic acid & 0.80 & 1.02 & 2.23 & - & 0.92 & - & 1.26 & 0.05 & - & f & 1.30 & 0.94 & - & - & 4.77 & 0.54 \\
\hline Octanoic acid & 0.94 & & & & & 0.46 & 0.66 & & 0.21 & & 0.05 & 0.26 & & 0.12 & 0.19 & \\
\hline Stearic acid & 21.30 & 21.52 & 20.61 & 19.37 & 14.43 & 16.35 & 13.98 & 4.71 & 10.97 & 9.65 & 12.68 & 19.06 & 14.63 & 19.21 & 11.13 & 1.90 \\
\hline Palmitic acid & 4.11 & 5.81 & - & 5.81 & - & 4.47 & - & & - & 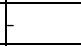 & - & - & - & 1.43 & - & - \\
\hline Toplam/Total & 27.42 & 30.02 & 22.49 & 25.98 & 19.97 & 21.89 & 15.9 & 5.12 & 12.31 & 10.71 & 21.93 & 23.51 & 22.69 & 21.75 & 18.14 & 9.91 \\
\hline \multicolumn{17}{|l|}{ Diğerleri/Others } \\
\hline Quinoline & 0.49 & F & 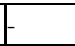 & F & - & - & F & 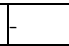 & F & F & - & - & E & - & - & - \\
\hline \begin{tabular}{|l|} 
2-Methoxy-3- \\
methylpyrazine
\end{tabular} & & - & & & & D & {[} & & & & & & - & & 2.16 & \\
\hline Amberoxid & - & 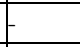 & 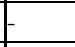 & 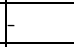 & - & - & - & 0.05 & 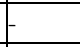 & 0.01 & 0.01 & - & - & 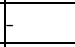 & - & - \\
\hline 5-Methylquinoxaline & - & 1.96 & & - & - & - & - & F & 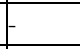 & 1.32 & - & - & - & 7 & - & 0.66 \\
\hline Phenethylamine & - & - & 0.37 & - & - & - & - & & - & [ & - & - & - & - & - & - \\
\hline Methyl octine carbonate & - & 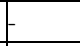 & - & - & - & 0.01 & - & & 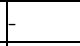 & 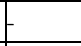 & - & - & - & - & - & 0.21 \\
\hline gamma-Butyrolactone & - & - & - & - & - & - & - & & - & 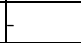 & - & - & - & - & - & 1.21 \\
\hline 4'-Methylacetophenone & 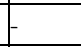 & 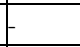 & - & $t$ & - & L & - & & - & 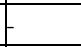 & - & - & - & 1 & - & 0.29 \\
\hline $\begin{array}{l}\text { Phenylacetaldehyde } \\
\text { dimethyl acetal } \\
\end{array}$ & & - & & 0.49 & & & - & & 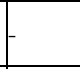 & & & 0.21 & & 0.31 & - & \\
\hline Toplam/Total & 0.49 & 1.96 & 0.37 & 0.49 & - & 0.01 & - & 0.05 & 5 & 1.33 & 0.01 & 0.21 & - & 0.31 & 2.16 & 2.37 \\
\hline
\end{tabular}

Gaz kromatografi-kütle spektrometresi (GCMS) ile uçucu bileşen ve yağ asitleri tayini

GC-MS ile yapılan aroma bileşenleri analizi sonucunda bal örneklerinin alkoller, aldehitler, ketonlar, alifatik asit ve esterler, hidrokarbonlar, terpenler ve yağ asitleri gibi farklı bileşik gruplarını içerdikleri görülmüştür (Çizelge 3) Balın kuru ağırlığının yaklașık \%95'lik kısmı karbonhidrat sınıfı bileşiklerden oluşmaktadır. Balın bu ana bileșenlerinin yanında proteinler (genellikle glikoz oksidaz, invertaz, diastaz vb. gibi farklı enzimler olarak), fenolik bileşikler (fenolik asitler ve flavonoidler), aroma bileşenleri ve suda çözünür vitaminler gibi bileşenler de eser miktarda 
bulunmaktadır. Balın içeriğindeki eser bileşenler, özellikle fenolik bileşenler ve aroma bileşenleri bal özünün toplandığ1 flora ile doğrudan ilişkilidir (Cianciosi vd., 2018). Bu eser bileşenler aynı zamanda balın tat ve aromasindan da sorumludur. B1, B3, B4, B5, B6, B8, B9, B12 ve B14 numaral1 bal örneklerinin aroma bileşenlerinin bağıl olarak $\% 40$ 'tan fazlasinin alifatik asitler ve esterlerinden oluştuğu görülmüsstür. Bu bileşen sınıfının, diğer bal örneklerinde de aroma bileşenleri içerisinde en yüksek bağıl bulunma oranına sahip olduğu tespit edilmiştir. B7 ve B9 örnekleri diğer ballardan farklı olarak alkol sınıfı bileşenleri daha yüksek bağıl bulunma oranında (\%25 ve \% 16) içermektedir. Balın aroması içeriğindeki uçucu bileşenlere bağlıdır. Yağ asitleri bu uçucu bileşenlerin oldukça az bir kısmını oluşturur (da Silva vd., 2016). Bu çalışmada analiz edilen bal örneklerinin uçucu bileşenlerinin önemli oranda yağ asidi içerdiği görülmüştür. Tornuk vd. (2013) tarafindan yapılan bir çalışmada, 20 farklı karışık çiçek balı örneğinin GC-MS tekniği ile aroma bileşenleri açısından incelendiği ve tespit edilen 88 farklı uçucu bileşiğin ballarda farklı oranlarda bulunduğu ve yine balların alifatik asitlerce zengin olduğu ortaya konulmuştur. Yapılan bir çalışmada Türkiye'de üretilen farklı bal tiplerinin aroma bileşenleri açısından incelendiği ve balların alkoller, aldehitler, alifatik/aromatik asitler ve esterleri, hidrokarbonlar, ketonlar ve terpenlerce zengin olduğu bildirilmiştir. Aynı çalışmada elde edilen sonuçların multifloral balların kimyasal içerik bazında standardize olmasının imkansız olduğunu gösterdiği de ifade edilmiştir (Çelemli, 2014). Balların aroma bileşenlerinin balın nektar kaynağının tespitinde bir parametre olabileceği ifade edilse de bu ancak tek nektar kaynaklı ballar için mümkündür. Çalışmamızda elde ettiğimiz sonuçlar da bu durumu desteklemektedir.

\section{SONUÇ}

Bu çalışma ile Bilecik ili ballarının bitkisel orijinleri ve bazı kimyasal özellikleri aydınlatılmak istenmiştir. Buna göre balların karışık çiçek balı niteliğinde, toplam fenolik madde miktarlarının Türkiye ballarının ortalaması içerisinde, şeker içeriklerinin ise Uluslararası Bal Kodeksi ve Türk Gida Kodeksi Bal Tebliği’ne uygun olduğu gözlenmiştir.

\section{TEŞEKKÜR}

Bal örneklerinin toplanmasinda desteklerini esirgemeyen Bilecik ili arıcılarına teşekkür ederiz.

\section{KAYNAKLAR}

Anonymous (2001). Codex Alimentarius standard for honey 12-1981. http://www.fao.org/faowho-codexalimentarius/codex-texts/liststandards/en

Anonymous (2012). Türk Gida Kodeksi Bal Tebligi (2012). Teblig no: 2012/58. Resmi Gazete, 28366.

Barcarolo, R., Centeleghe, M., Zanatta, P., Conte, L. S. (1998). GC-MS coupled with head space sampling with reverse carrier flow in sampling step applied to honey characterization. In: 5th international symposium of hyphenated technique in chromatography, Bruges, Belgium (pp. 11-21).

BEBKA (2018). Bilecik. T.C. Bursa Eskişehir Bilecik Kalkınma Ajansı, Bursa, Türkiye. https://www.bebka.org.tr/admin/datas/yayins/ 197/2018-12-doga-bilecik 1_1545052305.pdf

Bertoncelj, J., Doberšek, U., Jamnik, M., Golob, T. (2007). Evaluation of the phenolic content, antioxidant activity and colour of Slovenian honey. Food Chem, 105: 822-828.

Bogdanov, S. (1997). Charakterisierung von Schweizer Sortenhonigen. Agrarforschung, 4: 427430.

Bogdanov, S., Martin, P., Lullmann, C. (2002). Harmonised methods of the international honey commission. Swiss Bee Research Centre, FAM, Liebefeld.

Cianciosi D., Forbes-Hernández T.Y., Afrin, S., Gasparrini M., Reboredo-Rodriguez P., Manna, P.P., Zhang, J., Lamas, L.B., Martínez Flórez, S., Toyos, P.A., Quiles, J.L., Giampieri, F., Maurizio Battino, M. (2018). Phenolic compounds in honey and their associated health benefits: A review. Molecules, 23: 2322.

Cuevas-Glory, L.F., Pino, J.A., Santiago, L.S., Sauri-Duch, E. (2007). A review of volatile analytical methods for determining the botanical origin of honey. Food Chem, 103(3): 1032-1043. 
Çelemli, Ö.G. (2014). Comparing botanical origin and volatile compounds of some Turkish honey samples. Hacettepe J. Biol. \& Chem, 42(4): 459-468.

Çelemli, Ö.G., Özenirler, Ç., Ecem Bayram, N., Zare, G., Sorkun, K. (2018). Melissopalynological analysis for geographical marking of Kars honey. Kafkas Univ Vet Fak Derg, 24(1): 53-59.

da Silva, P.M., Gauche, C., Gonzaga, L.V., Costa, A.C.O., Fett, R. (2016). Honey: Chemical composition, stability and authenticity. Food Chem., 196: 309-323.

Devillers, J., Morlot, M., Pham-Delegue, M.H., Dore, J.C. (2004). Classification of monofloral honeys based on their quality control data. Food Chem, 86(2): 305-312.

Feller-Demalsy, M.J., Parent, J., Strachan, A.A. (1989). Microscopic analysis of honeys from Manitoba Canada. J Apic. Res. 28(1): 41-49.

Gül A., Pehlivan, T. (2018). Antioxidant activities of some monofloral honey types produced across Turkey. Saudi J Biol. Sci., 25: 1056-1065.

Güzel, N., Bahçeci, K.S. (2019). Çorum yöresi ballarının fenolik madde içerikleri ile renk ve antioksidan kapasiteleri arasındaki ilişki. Gıda, 44(6): 1148-1160.

Hasan, S.H. (2013). Effect of storage and processing temperatures on honey quality. JUBPAS, 6(21): 2244-2253.

Karadal, F., Yildırım, Y. (2012). Balın kalite nitelikleri, beslenme ve sağlık açısından önemi. Erciyes Üniv. Vet. Fak. Derg., 9(3): 197-209.

Kolaylı, S., Aliyazıcıoğlu, R., Ulusoy, E., Karaoğlu, S. (2008). Antioxidant and antimicrobial activities of selected turkish honeys. Hacettepe J. Biol. \& Chem, 36 (2): 163-172.

Kolaylı, S., Can, Z., Çakir, H. E., Okan, O. T., Yildiz, O. (2018). An investigation on Trakya region Oak (Quercus spp.) honeys of Turkey: their physico-chemical, antioxidant and phenolic compounds properties. Turk J Biochem, 43: 362374.

Mayda, N., Özkök, A., Sorkun, K. (2018). Some characteristic properties of chestnut and rhododendron honeys in Turkey. Hacettepe J. Biol. \& Chem, 46 (1): 135-145.

Moar, N.T. (1985). Pollen analysis of New Zealand honey. New Zeal. J Agr. Res., 28(1): 39-70.

Mutlu, C., Erbaş, M., Tontul, S.A. (2017). Bal ve diğer arı ürünlerinin bazı özellikleri ve insan sağllğı üzerine etkileri. Akademik Gıda, 15(1): 75-83.

Ocak, A., Öztürk, D., Kara, İ. (2017). Bilecik Florası. Bilecik Şeyh Edebali Üniversitesi Yayınları, 1. Bask1, ISBN: 978-605-65470-8-9.

Radovic, B.S., Careri, M., Mangia, A., Musci, M., Gerboles, M., Anklam, E. (2001). Contribution of dynamic headspace GC-MS analysis of aroma compounds to authenticity testing of honey. Food Chem, 72(4): 511-520.

Sagdic, O., Silici, S., Ekici, L. (2013). Evaluation of the phenolic content, antiradical, antioxidant, and antimicrobial activity of different floral sources of honey. Int. J. Food Prop, 16(3): 658-666.

Singh, I and Singh, S. (2018). Honey moisture reduction and its quality. J Food Sci Technol., 55(10): 3861-3871.

Singleton, V.L., Rossi, J.A. (1965). Colorimetry of total phenolics with phosphomolybdicphosphotungstic acid reagents. Am. J. Enol. Vitic, 16: 144-158.

Singleton, V.L., Orthofer, R., Lamuela-Raventós, R.M. (1999). Analysis of total phenols and other oxidation substrates and antioxidants by means of Folin-Ciocalteu reagent. Methods Ensymol., 299: 152-178.

Slinkard, K. Singleton, V.L. (1977). Total phenol analysis: automation and comparison with manual methods. Am. J. Enol. Vitic, 28: 49-55.

Soria, A.C., Martínez-Castro, I., Sanz, J. (2003). Analysis of volatile composition of honey by solid phase microextraction and gas chromatographymass spectrometry. J Sep Sci., 26(9-10): 793-801.

Sorkun, K. (2008). Türkiye'nin nektarl bitkileri, polenleri ve ballar. Palme Yayıncillk.

Tornuk, F., Karaman, S., Ozturk, I., Toker, O. S., Tastemur, B., Sagdic, O., Dogan, M. and Kayacier, A. (2013). Quality characterization of 
artisanal and retail Turkish blossom honeys: Determination of physicochemical, microbiological, bioactive properties and aroma profile. Ind. Crop. Prod., 46: 124-131.
Tutkun, E., 2006. Arıcılık Tekniği. Önder Matbaacilı, Ankara, Türkiye.

Wodehouse, R.P. (1935). Pollen grains. McgrawHill Book Company, Inc; New York. 